\title{
Rancang Bangun Sistem Kontrol Keamanan Gerbang Menggunakan Raspberry Pi B+ Berbasis Web
}

\author{
Arief Saptono $^{1}$, Abdul Malik*2, Muhamad Satim ${ }^{3}$ \\ ${ }^{1}$ Program Studi Sistem Informasi Universitas Raharja, ${ }^{2,3}$ Program Studi Sistem Komputer \\ Universitas Raharja \\ Email: ${ }^{1}$ arief.saptono@ raharja.info, *2abdul.malik@ raharja.info, \\ ${ }^{3}$ muhamad.satim@raharja.info
}

\begin{abstract}
Abstrak
Teknologi komputer dan informasi dari waktu ke waktu selalu mengalami perkembangan, baik dari segi hardware, software dan internet menjadi salah satu hal yang terpenting pada saat ini. Semakin banyaknya penerapan teknologi komputer akan membuat peran komputer semakin penting untuk semakin maju (modernisasi). Sistem keamanan masih belum cukup efektif dan efisien, sehingga diperlukan suatu kontrol menggunakan website sehingga membantu proses pengendalian keamanan di gerbang. Sistem ini tidak hanya digunakan di perkantoran, melainkan dapat dipergunakan dalam keamanan rumah dan sebagainya. Sehingga diperlukan suatu sistem keamanan, dimana pada sistem kontrol keamanan ini menggunakan sebuah alat untuk memonitor keamanan secara realtime melalui web browser yaitu webcam (Web Camera). Sistem kontrol gerbang berbasis web dapat dirancang menggunakan Raspberry Pi B +. Dari penjelasan yang telah dijelaskan diatas peneliti membuat sebuah alat pengatur gerbang yang dihubungkan ke Mikrokontroler menggunakan Web Browser agar dapat membuka dan menutup gerbang, sehingga diharapkan adanya aplikasi sistem keamanan ini dapat memberikan rasa kenyamanan, selain itu tentunya dengan adanya aplikasi sistem keamanan tersebut dapat mengurangi angka kejahatan yang terjadi baik pencurian maupun kejahatan lainnya.
\end{abstract}

Kata Kunci : Sistem Kontrol, Raspberry Pi B+, Keamanan Gerbang.

\begin{abstract}
Computer and information technology from time to time are always experiencing developments, both in terms of hardware, software and the internet being one of the most important things at this time. The increasing number of applications of computer technology will make the role of computers increasingly important to be more advanced (modernization). The security system is still not effective and efficient enough, so that a control using a website is needed to help the security control process at the gate. This system is not only used in offices, but can be used in home security, etc. So we need a security system, where the security control system uses a tool to monitor realtime security via a web browser, namely a webcam (Web Camera). A web-based gate control system can be designed using the Raspberry Pi B +. From the explanation mentioned above, the researcher made a gate control device that was given to the Microcontroller using a Web Browser in order to open and close the gate. So it is hoped that this security system application can provide a sense of comfort, in addition, of course, with this system application it can reduce the number of crimes that occur both crimes and other crimes.
\end{abstract}

Keywords: Control System, Raspberry Pi B +, Security Gate. 


\section{Pendahuluan}

Teknologi komputer dan informasi dari waktu ke waktu selalu mengalami perkembangan, baik dari segi hardware, software dan internet menjadi salah satu hal yang terpenting pada saat ini dan sudah banyak yang menggunakannya, namun tidak menutup kemungkinan berkembangnya kreativitas dengan konsep yang berbeda bahkan alat dalam aplikasinya, mulai dari yang paling sederhana hingga yang menggunakan teknologi canggih seperti teknologi kamera CCTV dengan sistem offline dan sistem online yang menggunakan IP camera. Sistem keamanan masih belum cukup efektif dan efisien, sehingga diperlukan suatu kontrol melalui website sehingga membantu proses pengendalian keamanan di gerbang. Sistem ini tidak hanya digunakan di perkantoran, melainkan dapat dipergunakan dalam keamanan rumah dan sebagainya. Sehingga diperlukan suatu sistem keamanan, dimana pada sistem kontrol keamanan ini menggunakan sebuah alat untuk memonitor keamanan secara realtime melalui web browser yaitu webcam (Web Camera). Meningkatnya jumlah kejahatan dan pembobolan yang terjadi saat ini menjadikan sistem keamanan sebagai kebutuhan mutlak untuk diimplementasikan, untuk itu diperlukan suatu sistem keamanan yang dapat menjaga secara penuh waktu untuk melindungi aset dan privasi. Sehingga diharapkan adanya aplikasi sistem keamanan ini dapat memberikan rasa aman dan nyaman, selain itu tentunya dengan adanya aplikasi sistem keamanan tersebut dapat mengurangi angka kejahatan yang terjadi baik pencurian maupun kejahatan lainnya. Gerbang merupakan hal terpenting dalam sistem keamanan rumah, perusahaan dan kantor pemerintahan, serta gedung penting lainnya. Sebab, gerbang tersebut berfungsi sebagai akses utama untuk masuk. Memasang sistem keamanan di pintu gerbang merupakan salah satu bentuk otomasi sebagai dampak positif dari perkembangan teknologi. Dengan otomatisasi ini maka peran manusia akan tergantikan oleh alat atau mesin, karena pada dasarnya pintu gerbang akan terbuka dengan sendirinya jika password yang dimasukkan dengan benar sehingga diharapkan setiap gerbang tidak harus terus menerus dijaga oleh manusia [1]. Karena sistem ini dilengkapi dengan alarm yang akan berbunyi bila dibuka secara paksa, maka sistem cerdas yang akan dibangun pada penelitian ini mengenai Sistem Kontrol Gerbang menggunakan Raspberry Pi B+ yang berfungsi sebagai server dan media kontrol rangkaian.

\section{TINJAUAN PUSTAKA}

\section{Raspberry Pi}

Disampaikan oleh Dinata (2017) [2], Raspberry Pi merupakan komputer berukuran kecil, seukuran sabun mandi besarnya. Karena Raspberry Pi merupakan komputer yang secara fungsional tidak berbeda dengan komputer besar di sekolah, rumah, kantor ataupun laptop. Artinya Raspberry Pi dapat digunakan untuk membuat dokumen, menghitung, menggambar, browsing internet, mendownload, mencetak dokumen, menonton film, bermain musik, bermain game dan apapun. Karena ukurannya yang kecil, Raspberry Pi dapat dibawa kemana-mana dan Raspberry Pi juga membutuhkan listrik yang sangat sedikit untuk beroperasi. Artinya Raspberry Pi menghemat biaya dalam penggunaan listrik

\section{LITERATURE REVIEW}

Literuture Review dapat dikatakan sebagai sesuatu tindakan atau pekerjaan memeriksa dan meninjau kembali penelitian milik orang lain sebagai acuan untuk penelitian kita, berikut Literature Review pada penelitian ini :

1. Penelitian yang dilakukan oleh Qorni dkk [3] yang berjudul: "Perancangan Sistem Kontrol Otomatis Berbasis Web Menggunakan Raspberry Pi 3 pada Smartphone". Sistem yang 
dibuat dapat memudahkan pengendalian perangkat elektronik dengan melakukan pengendalian secara terpusat pada smartphone Android.

2. Penelitian yang dilakukan oleh Muslimin dkk [4] yang berjudul: "Rancang Bangun Sistem Keamanan dan Pemantau Tamu pada Pintu Rumah Pintar Berbasis Raspberry Pi dan Chat Bot Telegram". Sistem yang dibuat memudahkan pengguna untuk melihat tamu yang datang atau orang yang berada di depan pintu dengan smartphone secara real-time.

3. Penelitian yang dilakukan oleh Nas dkk [5] yang berjudul: "Sistem Pengontrolan Pintu Gerbang Berbasis Iot". Dengan memanfaatkan perkembangan teknologi yaitu Internet of Things (IoT) maka sistem kendali gerbang dapat diakses dimana saja. IoT menggunakan internet yang menghubungkan sistem kendali dan ponsel pengguna. Pembuatan sistem ini dimulai dengan menganalisis kebutuhan, merancang sebagai dasar pembuatan sistem, menguji prototipe, dan mengevaluasi kinerja sistem kendali gerbang. Setelah semua persyaratan sistem kendali terpenuhi selanjutnya dilakukan analisis evaluasi kinerja.

\section{Metode Penelitian}

\section{Metode Pengumpulan data}

Untuk pengumpulan data, peneliti menggunakan beberapa metode yaitu: Metode Observasi, dalam metode ini peneliti harus mereview apa yang sedang diteliti yaitu dengan melakukan observasi langsung pada sistem yang sedang berjalan dengan terlibat dalam proses pembuatan sistem yang ada. Kemudian dari observasi tersebut, peneliti mengumpulkan data-data yang dibutuhkan untuk dianalisis dalam rangka mengembangkan sistem. Selanjutnya adalah Metode Wawancara, dalam metode ini peneliti harus melakukan sesi tanya jawab dengan narasumber salah satunya adalah owner tempat peneliti melakukan penelitian. Metode ini digunakan untuk mendapatkan data yang relevan sesuai dengan kebutuhan sistem.

\section{Hasil Dan Pembahasan}

\section{A. Diagram Blok}

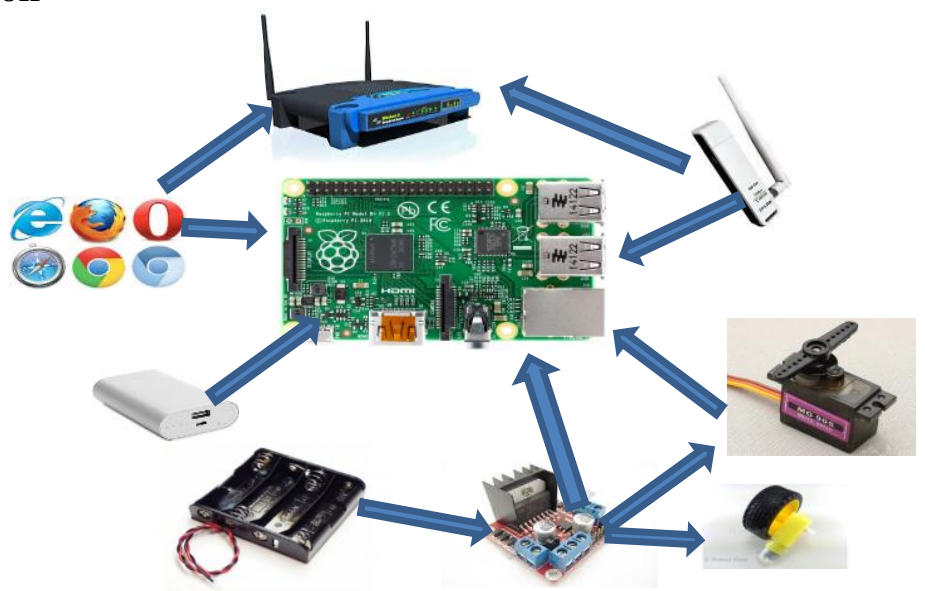

Gambar 1. Diagram Blok

Adapun uraian dan penjelasan dari Gambar 1 Diagram Blok diatas adalah sebagai berikut :

1. Wireless Modem adalah perangkat untuk memberikan alamat IP kepada Tp-Link Raspberry Pi B +. 
2. Web browser adalah aplikasi yang digunakan untuk membuka dan menjalankan sistem kontrol gerbang.

3. Raspberry Pi merupakan alat yang digunakan untuk menjalankan program yaitu kontrol gerbang.

4. Power Bank adalah sebuah perangkat yang digunakan untuk memasukkan energi listrik pada Raspberry $\mathrm{PiB}+$ agar perangkat tersebut dapat berjalan tanpa harus mencolokkan perangkat tersebut ke outlet listrik.

5. Tp-Link adalah perangkat yang menghubungkan Raspberry Pi B + untuk menerima dan mengirim sinyal untuk komunikasi antara wireless dan router.

6. Battery Pack adalah rangkaian baterai untuk memberikan tenaga listrik pada motor DC dan motor servo.

7. L298N adalah modul motor yang digunakan untuk menggerakkan dan mengendalikan motor DC.

8. Motor DC adalah sirkuit elektronik yang dapat menggerakkan pintu gerbang.

9. Motor servo adalah alat listrik yang digunakan untuk mengontrol pergerakan pintu gerbang yaitu mengunci dan membuka pintu gerbang

\section{B. Raspberry Pi B + Seri Sistem Minimum}

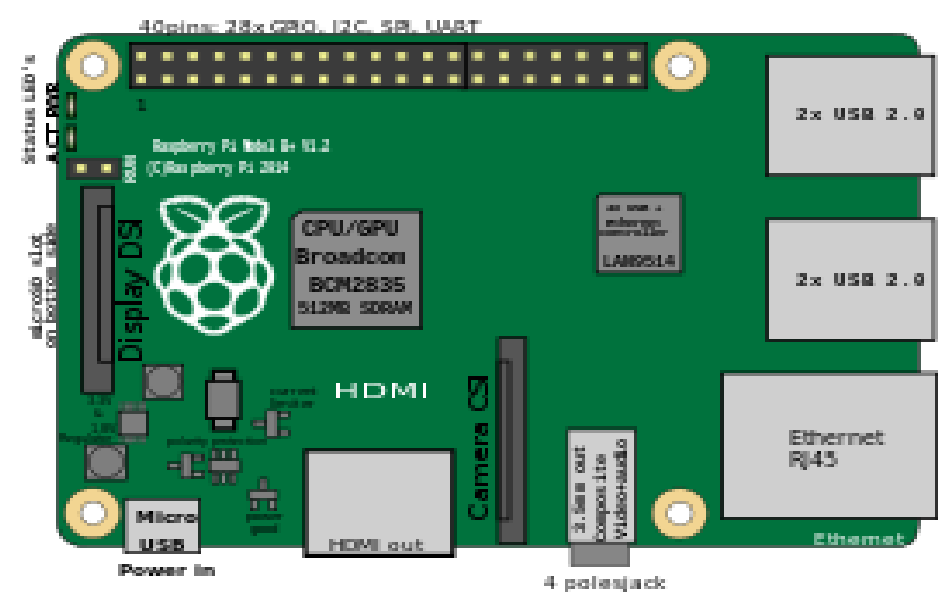

Gambar 2. Rangkaian Raspberry Pi B+

CPU Raspberry Pi B+ menggunakan sebuah ARM1179JZF-S frekuensi $700 \mathrm{MHz}$ sedangkan GPU menggunakan Broadcom BCIM 2835 frekuensi 250MHz. serta memiliki RAM sebesar $512 \mathrm{MB}$. Dari ketiga komponen tersebut dapat dipasang secara bertumpuk agar ruang pada mainboard berkurang.

\section{Pengujian Rangkaian Catu Daya untuk Raspberry Pi B+}

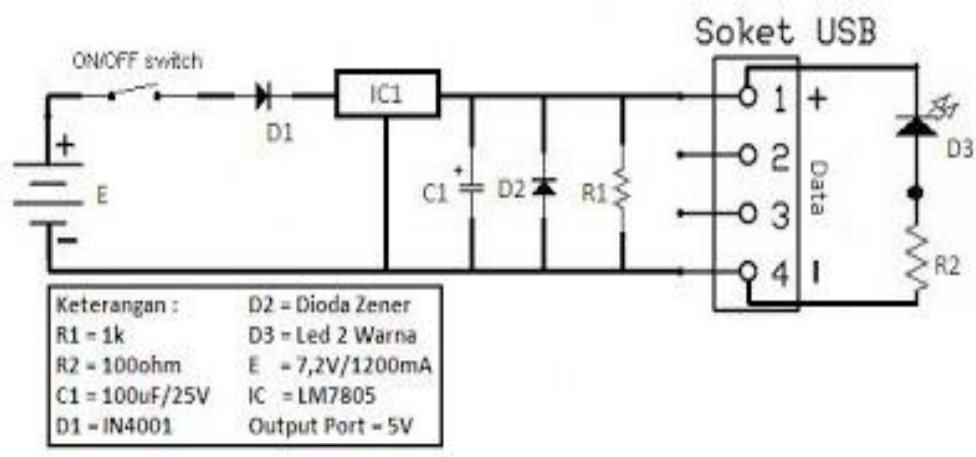

Gambar 3. Pengujian Rangkaian Catu Daya Raspberry Pi B+ 
Setelah melakukan pengujian sesuai Gambar 3 menghasilkan tegangan yang didapat dari Power Supply adalah 5 Volt dengan besar arus 1 Ampere. Dengan hasil tersebut maka cukup untuk dapat menyalakan Raspberry Pi B+.

Tabel 1. Menguji Catu Daya pengontrol motor L298N

\begin{tabular}{|c|c|c|c|}
\hline $\begin{array}{c}\text { Jenis } \\
\text { Baterai }\end{array}$ & Jumlah baterai & $\begin{array}{c}\text { Tegangan } \\
\text { (Volt) }\end{array}$ & Hasil dan durasi \\
\hline $\mathrm{Abc}$ & 2 buah & 3 & $\begin{array}{c}\text { Motor dc bergerak lambat } \\
\text { durasi pemakaian } 30 \\
\text { menit }\end{array}$ \\
\hline $\begin{array}{c}\text { ABC } \\
\text { ALkaline }\end{array}$ & 4 buah & 6,3 & $\begin{array}{c}\text { Motor dc bergerak nomal } \\
\text { dengan durasi yang cukup } \\
\text { lama 2-3 jam }\end{array}$ \\
\hline $\begin{array}{c}\text { UltraFire } \\
\text { Rechargable }\end{array}$ & 2 buah & 7,5 & $\begin{array}{c}\text { Motor DC bergerak cepat } \\
\text { dengan durasi 1-2 jam }\end{array}$ \\
\hline
\end{tabular}

Berdasarkan hasil pengujian diatas maka peneliti menyimpulkan bahwa jika baterai $\mathrm{ABC}$ ingin tetap stabil maka akan menggunakan banyak ruang karena menggunakan 4 (empat) buah baterai yang tidak terisi tegangan listrik kemudian 2 (dua) Baterai UltraFire Rechargable dapat memberikan tegangan yang cukup besar sehingga masih dalam toleransi kontrol motor L298n dan baterai dapat diisi ulang dengan tegangan listrik, sehingga penggunaan baterai lebih hemat.

Tabel 2. Pengujian Kontrol Melalui berbagai perangkat

\begin{tabular}{|l|l|l|}
\hline \multicolumn{2}{|c|}{ Perangkat } & \multicolumn{1}{|c|}{ Hasil } \\
$\begin{array}{c}\text { Nama } \\
\text { Perangkat }\end{array}$ & Web Browser & \\
\hline Ipad & Safari & $\begin{array}{l}\text { 1. Tombol kontrol terbuka } \\
\text { 2. Pengendalian berjalan dengan baik }\end{array}$ \\
\hline $\begin{array}{l}\text { HandPhone } \\
\text { Android }\end{array}$ & Chrome Mobile & $\begin{array}{l}\text { 1. Tombol kontrol terbuka } \\
\text { 2. Pengendalian berjalan dengan baik }\end{array}$ \\
\cline { 2 - 3 } & Built in Browser & $\begin{array}{l}\text { 1. Tombol kontrol terbuka } \\
\text { 2. Pengendalian masih bisa dilakukan } \\
\text { dengan baik }\end{array}$ \\
\hline Laptop/PC & Google Chrome & $\begin{array}{l}\text { 1. Tombol kontrol terbuka } \\
\text { 2. Pengendalian berjalan dengan baik }\end{array}$ \\
\hline
\end{tabular}

Berdasarkan hasil pengujian diatas peneliti telah mencoba dengan berbagai alat web browser yang digunakan dalam pembuatan aplikasi ini dan dari hasil pengujian masing-masing perangkat dinyatakan dapat digunakan dalam aplikasi sistem yang dibuat. 


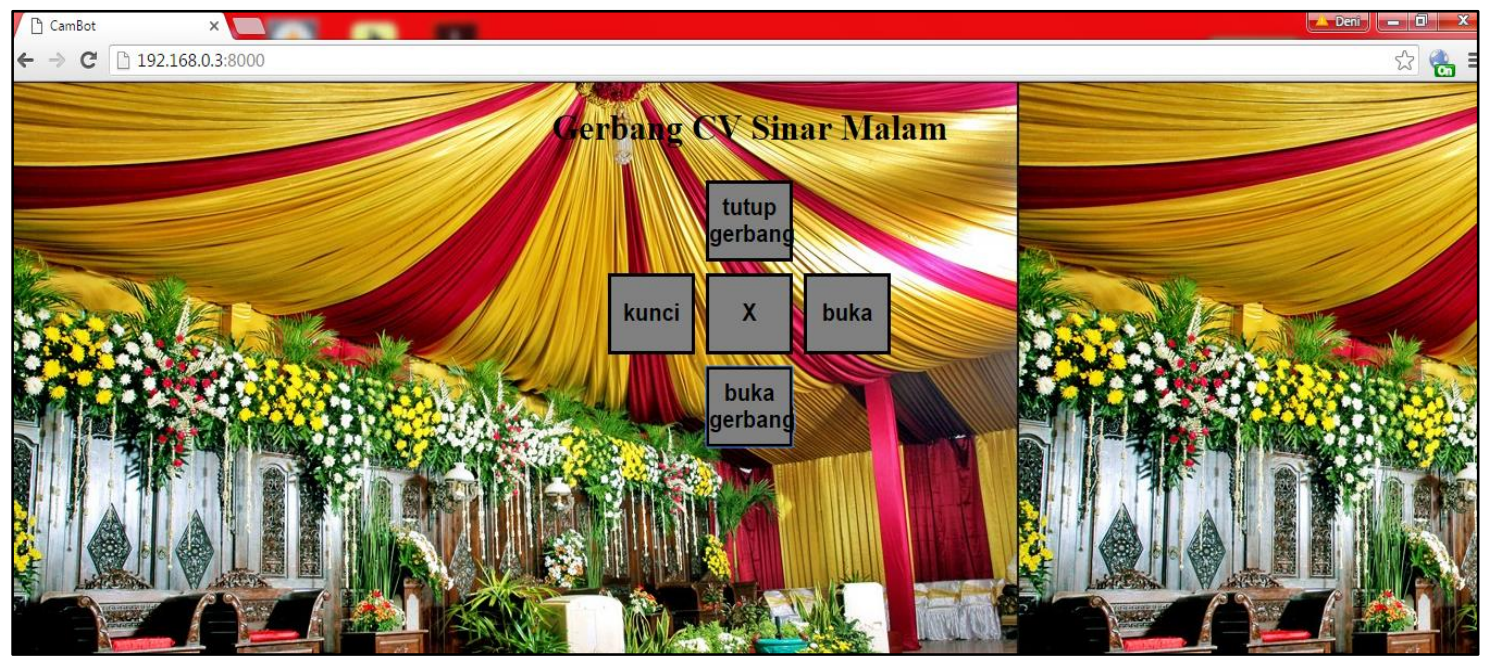

Gambar 4. Tampilan Kontrol di Web Browser

Tampilan pada gambar 4 diatas merupakan antarmuka kontrol yang ada di Web Browser.

Berikut merupakan listing programnya :

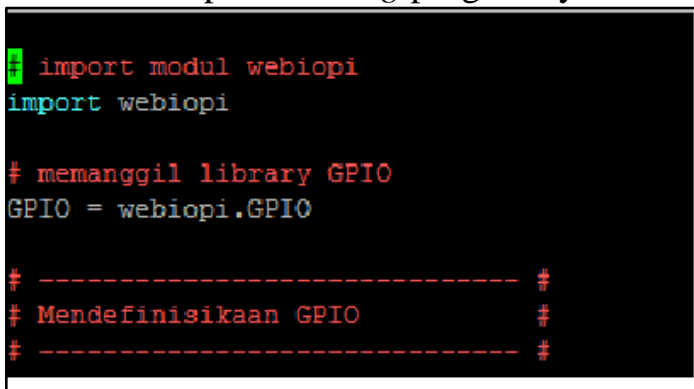

Gambar library WebIOPi

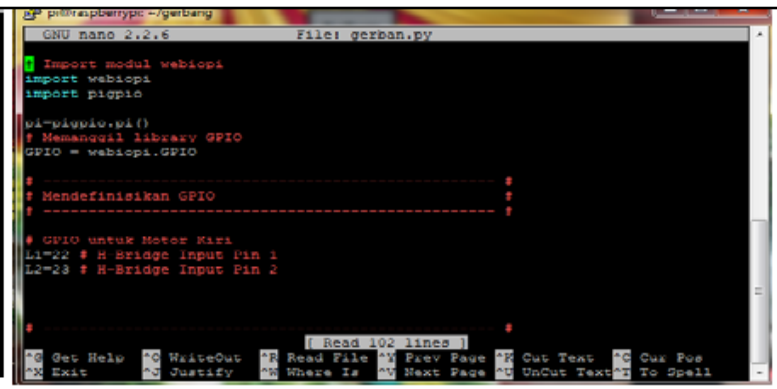

Gambar Pin GIOP

Gambar 5. webIOPi dan Pin GIOP

Pada gambar 5 diatas menunjukkan bahwa webIOPi menjadi web server dan mengatur GPIO sesuai kebutuhan, sedangkan pada GPIO digunakan untuk mengontrol sebanyak 4 pin yaitu GPIO pin 17, 22, dan 24. Pin tersebut diwakili oleh variabel untuk memudahkan program.

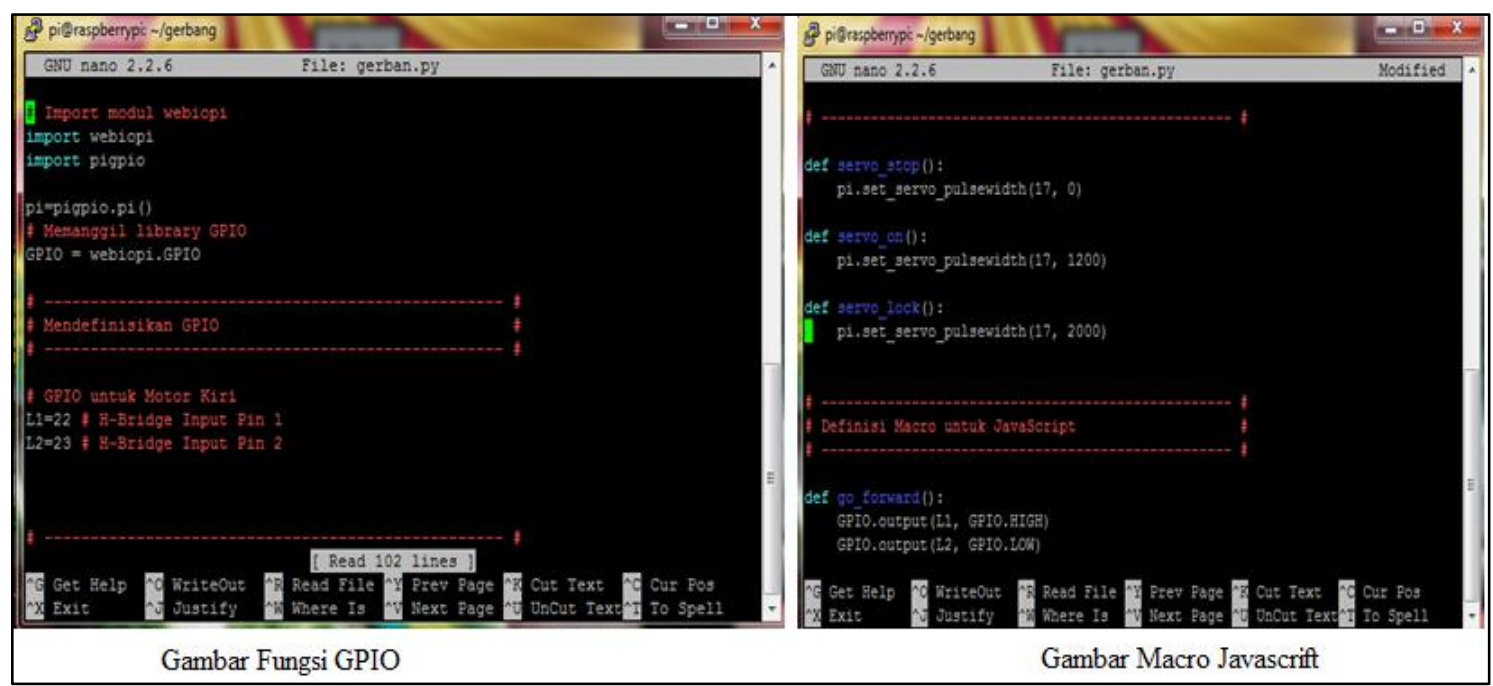

Gambar 6. Fungsi GIOP dan Macro Javascript 
Pada gambar 6 tersebut fungsi GPIO menjelaskan bahwa ketika variabel untuk pin telah dibuat, mereka dapat membuat fungsi untuk variabel tersebut. Fungsi yang telah dibuat tersebut digunakan untuk mengaktifkan motor dc mana yang akan on dan motor dc mana yang akan off ketika fungsi ini dipanggil. Sedangkan fungsi Macro adalah membuat pintu gerbang bergerak sesuai keinginan, oleh karena itu dibuat fungsi baru yang menggabungkan fungsi sebelumnya. Fungsi baru inilah yang akan membuat pintu gerbang bergerak maju, membuka dan menutup serta berhenti. fungsi inilah yang akan turn_left, turn_right, dan stop. Fungsi tersebut akan ditambahkan ke dalam Macro untuk Java.

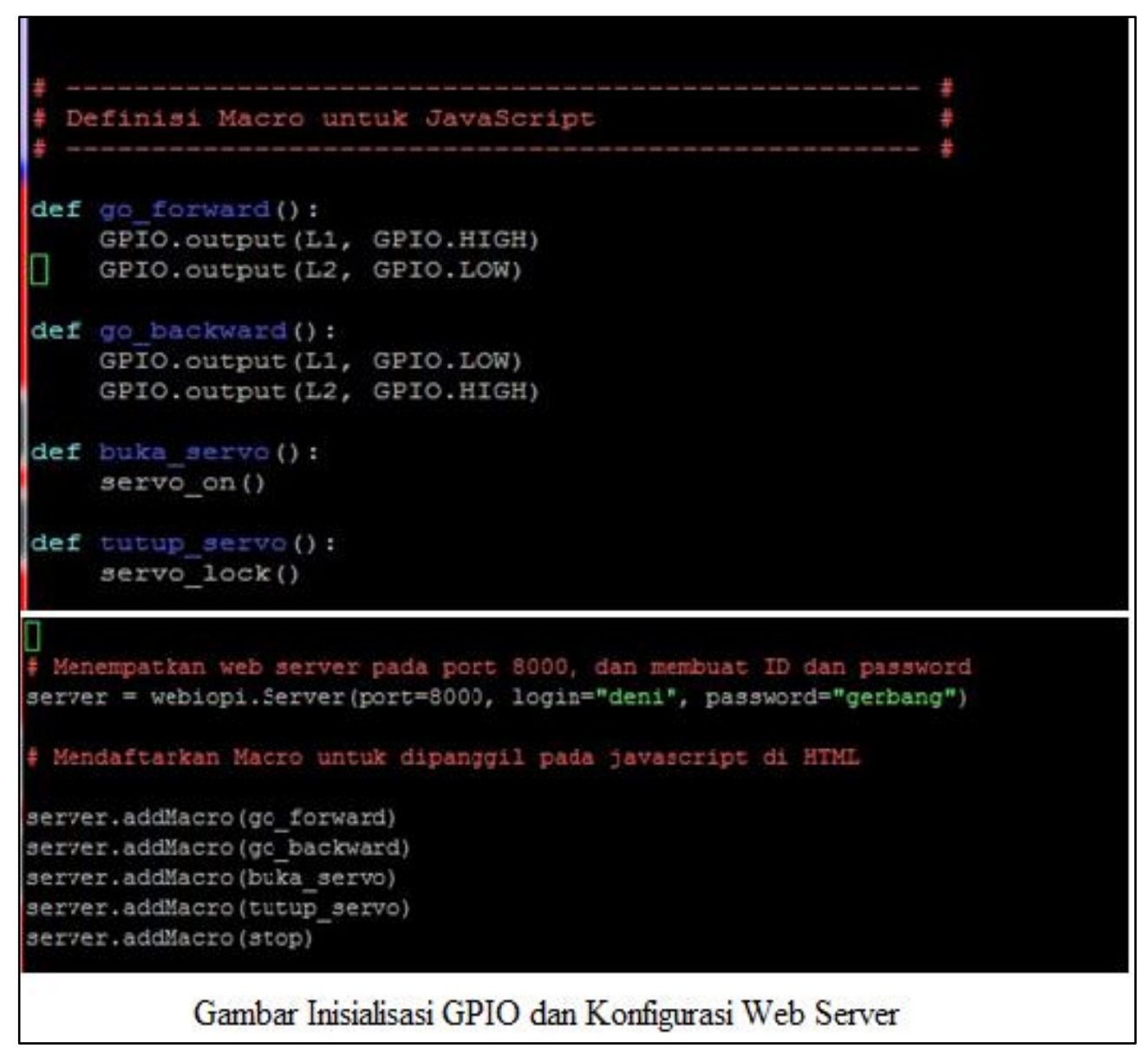

Gambar 7. Inisialisasi GPIO

Untuk keterangan gambar 7 diatas, pada bagian Inisialisasi set GPIO sebagai keluaran (output) dan pada bagian ini harus ditambahkan karena GPIO dapat dikonfigurasi dari berbagai fungsi dan fungsi yang awalnya bukan keluaran dan pada konfigurasi server web pada aplikasi webiopi telah menginstal server web Apache dan di sini kita dapat mengatur server web pada port mana pun yang diinginkan dengan id login dan kata sandi dapat kita atur.

Pada titik ini kami mengatur aplikasi untuk berjalan pada port 9000 dengan id "deni" dan password "gateway". Setelah server dikonfigurasi, kita dapat mendaftarkan fungsi makro apa pun yang ingin kita panggil dalam Javascript di tata letak halaman web nanti. 


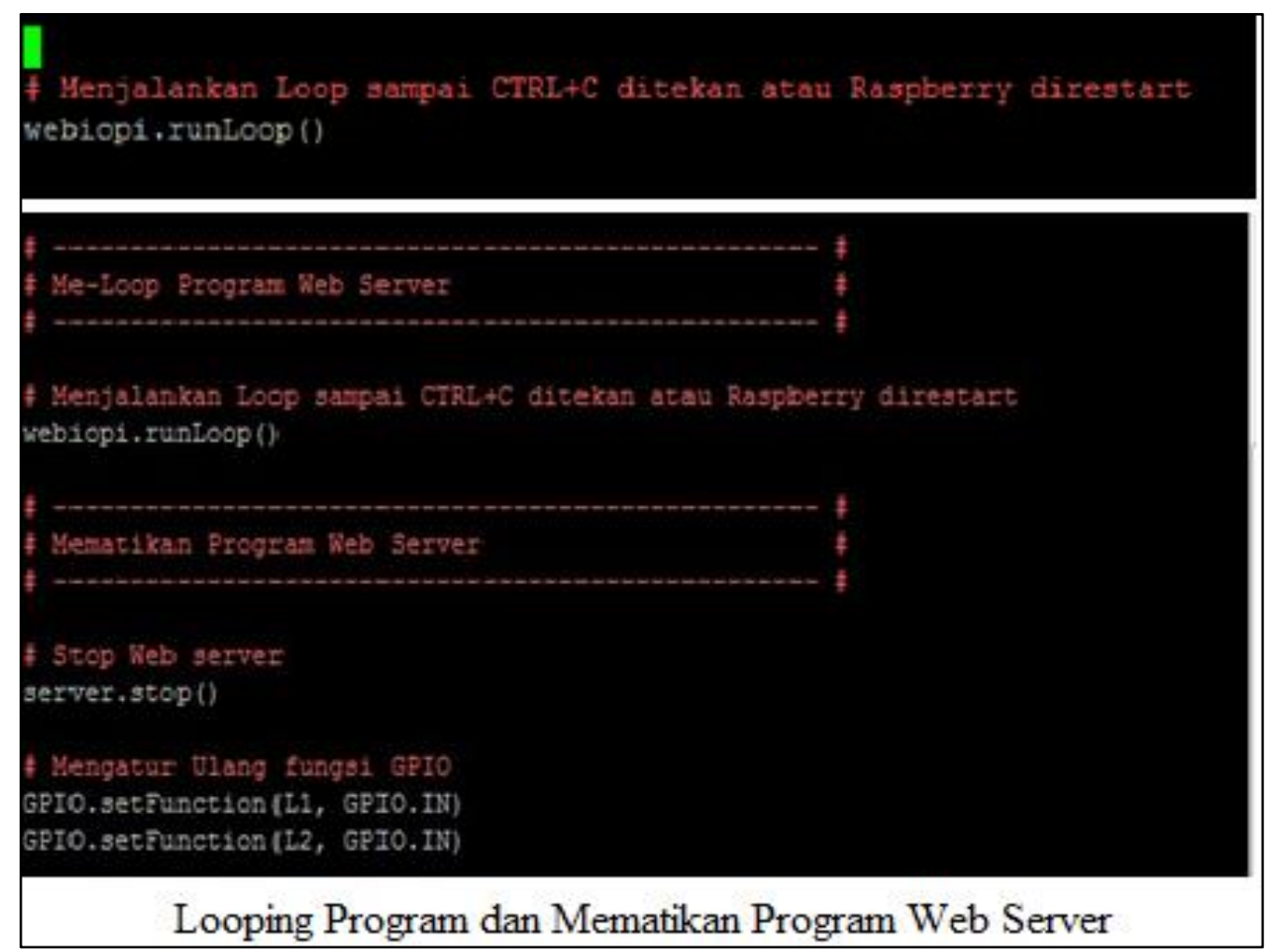

Gambar 8. Looping Program

Pada gambar 8 diatas Barisan kode yang ditulis berfungsi untuk menjalankan program loop. Pengulangan program akan terus berlanjut sampai menekan tombol keyboard CTRL $+\mathrm{C}$ atau dengan cara mematikan mesin dengan paksa sehingga jaringan komputer terhenti, jika pengulangan program terhenti, maka GPIO harus diaktifkan sesuai posisi awal tanpa harus reboot Raspbian. Hal tersebut dilakukan agar GPIO yang telah digunakan tidak dapat di-recall ketika sistem operasi Raspbian masih berjalan.

\section{Kesimpulan}

Rancangan sistem kontrol keamanan gerbang memiliki manfaat untuk dapat membantu proses penjagaan keamanan gerbang. Dengan adanya sistem kontrol gerbang ini, dapat mempermudah petugas dalam menajga keamanan gerbang sehibngga tidak perlu lagi dijaga terus menerus selama 24 jam. Untuk mendapatkan sistem kontol gerbnag yang dapat mengurangi resiko kehilangan atau pembobolan maka dibuatlah sistem kontrol gerbang menggunakan Raspberry Pi $\mathrm{B}+$

\section{Saran}

Diharapkan kedepannya dalam koneksi jaringan web dapat di kembangkan lagi dari localhost ke jaringan internet agar lebih efektif dalam penggunaannya yang tidak terlalu memperhatikan jarak dan efisien dalam penggunaan kabel LAN, kemudian IP address raspberry Pi itu akan lebih sederhana saat menggunakan IP public.

Dan sistem dapat diubah menjadi sistem yang lebih canggih lagi menggunakan sensor sidik jari dari sistem sebelumnya. Selain itu perlu peningkatan keakuratan pengguna dan memproses sistem kontrol gerbang guna menghindari resiko kehilangan dan pembobolan. 


\section{Daftar Pustaka}

[1] Suryansah, A., Habibi, R., \& Awangga, R, M. 2020. Penggunaan Face Recognition untuk akses ruangan. Bandung : Kreatif Industri Nusantara.

[2] Dinata, A. 2017. Physical Computing dengan Raspberry Pi. Jakarta : PT Elex Media Komputindo.

[3] Qorni, Wais Al., Anugrah, A \& Elvan, Y. 2016. Perancangan Sistem Kontrol Otomatis Berbasis Web Menggunakan Raspberry Pi 3 pada Smarthome. Jurnal Al-Fiziya, 1(2) 15-24. https://doi.org/10.15408/fiziya.v1i2.9501

[4] Muslimin, Zaenab dkk. 2019. Rancang Bangun Sistem Keamanan dan Pemantau Tamu pada Pintu Rumah Pintar Berbasis Raspberry Pi dan Chat Bot Telegram. Jurnal KPE, 23(2) 121-128. https://doi.org/10.25042/jpe.112019.05

[5] Nas, M., Harfiana, H., \& Armila, N. 2019. Sistem Pengontrolan Pintu Gerbang Berbasis Iot. Prosiding Seminar Nasional Penelitian \& Pengabdian Kepada Masyarakat, 42-46 